\title{
Structural, Optical and Thermoelectrical Properties of Mercury Chromium Sulfide Thin Films Deposited By Novel Chemical Route
}

\author{
H.B.Patil ${ }^{1}$, S.V.Borse ${ }^{2}$, R.R.Ahire ${ }^{3}$ \\ ${ }^{1}$ Department of Physics, R.C.Patel ACS College,Shirpur-425405(M.S.) India. \\ ${ }^{2}$ Department of Physics, S. S. V. P. S, ACS, College, Shindkheda-425406, (M.S.) India. \\ ${ }^{3}$ Department of Physics, S.G.Patil ACS College,Sakri (M.S.) India.
}

\begin{abstract}
Semiconducting mercury chromium sulfide thin films were deposited on glass substrate using simple, quick chemical bath deposition method using the mixed aqueous solution of mercury chloride, chromium trioxide, thiourea, EDTA and ammonia. The EDTA was used as the complexing agent. The preparative parameters such as temperature, molar concentration, deposition time and thiourea concentration have been optimized. Thin films of $\mathrm{Hg}_{x} \mathrm{Cr}_{2-x} \mathrm{~S}_{4}(\mathrm{X}=0.2)$ with different thickness were prepared by changing the deposition time at $65{ }^{\circ} \mathrm{c}$. The structural, morphological, optical and electrical studies were performed by X-ray diffraction, scanning electron microscopy, UV-VIS spectrophotometer and TEP methods respectively. The films are very adherent to the substrate and cubic structure in nature with the preferential orientation (2 20$)$. The optical studies showed a film of direct band gap is $2.13 \mathrm{eV}$. Thermoelectric properties show a positive sign exhibiting $P$ - type semiconducting nature of film.
\end{abstract}

Keywords: Thin film, XRD, SEM, UV, TEP.

\section{Introduction}

Mercury chromium sulfide is a chalcogenide metal sulfide semiconductor of the II-VI group compound semiconductors. The technological interests in polycrystalline-based devices are mainly caused by their low production cost [1]. As a ternary Cr-based chalcogenide $\mathrm{HgCr}_{2} \mathrm{~S}_{4}$ performed a variety of applications in various magneto-optical and optoelectronics devices $[2,3]$ as well as magnetocapacitive or magnetoelectric effect devices [3-7]. Doping with chromium to $\mathrm{HgS}$ window material improves the electrical and optical properties of thin films. Mercury Chromium sulfide is a chalcogenide metal sulfide semiconductor with an insulating structure [8]. Many techniques have been reported in the deposition of thin films such as evaporation, sputtering, spray pyrolysis, molecular beam epitaxy, and photochemical deposition. There is a problem in each of these deposition methods $[9,10]$. Amongst all, chemical bath deposition (CBD) is simple, easy to handle, low cost and is suitable for a large area deposition and capable of yielding good quality thin films [11]. The characteristics of chemically deposited $\mathrm{HgCr}_{2} \mathrm{~S}_{4}$ thin films by CBD strongly depend on the growth conditions.

In the present study, the chemical bath process is performed by slow release of $\mathrm{S}^{2-}$ and controlled free $\mathrm{Hg}^{2+}$ and $\mathrm{Cr}^{2+}$ react to form $\mathrm{HgCr}_{2} \mathrm{~S}_{4}$ nuclei on glass substrate and in the bath solution in the form of precipitation. The growth, structural, surface morphological, optical and thermoelectric properties have been studied.

\section{Experimental}

In the present investigation, thin films of $\mathrm{Hg}_{\mathrm{x}} \mathrm{Cr}_{2-\mathrm{x}} \mathrm{S}_{4}(\mathrm{X}=0.2)$ are grown on glass substrate by chemical bath deposition technique. All AR grade (MERCK) chemicals are used for growth of $\mathrm{Hg}_{x} \mathrm{Cr}_{2-\mathrm{x}} \mathrm{S}_{4}$ thin films. For the deposition of $\mathrm{Hg}_{\mathrm{x}} \mathrm{Cr}_{2-\mathrm{x}} \mathrm{S}_{4}$ solutions of $\mathrm{HgCl}_{2}, \mathrm{CrO}_{3}$ and $\mathrm{NH}_{2}-\mathrm{CS}-\mathrm{NH}_{2}$ are prepared separately of concentration $0.1 \mathrm{M}$ using double distil water as solvent and mixing them in non-stoichiometric proportion. EDTA is used as complexing agent. $\mathrm{pH}(10-11)$ of the reaction mixture was adjusted by adding ammonia. The deposition carried out in borosil glass pot of capacity $100 \mathrm{ml}$ is used to put chemical reactant in the form of solution, served as chemical reaction bath. This chemical reaction bath is put under constant temperature oil bath. The chemical reactant in form of solution is stirred by magnetic stirrer. Well cleaned glass microslides are dipped vertically in the chemical reaction bath by providing support to glass pot of the reaction bath. The stirring speed of magnetic stirrer is so adjusted that the solution can stir slowly during the deposition process. After deposition of $\mathrm{HgCr}_{2} \mathrm{~S}_{4}$ thin films, the substrate are taken out and washed with double distilled water and dried in air. Finally, they are preserved in an air tight container. Good quality samples were deposited at optimized temperature, time of deposition, speed of solution rotation and $\mathrm{pH}$ at $65^{\circ} \mathrm{C}, 120 \mathrm{~min}, 40 \mathrm{rpm}$ and 10 values respectively. The thickness of deposited thin films is measured by the weight difference technique. The structural properties of the films are analyzed by using Bruker AXS D8 Advanced model X-ray diffractometer $\left(\mathrm{CuK}_{\alpha}\right.$ radiation; $\lambda=$ $0.15405 \mathrm{~nm}$ ) and the grain size is determined from the Scherrer formula. The film surface morphology was 
investigated using scanning electron microscopy (FE-SEM HITACHI S4800 II). The optical absorption studies were carried out using UV-VIS spectrophotometer (UV-VIS 2400 SHIMADZU) in the 200-800 nm wavelength range. Thermoemf of the samples was measured by TEP by "Scientific Equipment and Services, Roorkee".

\section{Results and Discussions}

\subsection{Impact of Preparative Parameters}

\subsubsection{Impact of Bath Temperature}

Figure 1 shows the variation of film thickness with deposition temperature, keeping other parameters constant. The temperature of chemical bath was changed from $40{ }^{0} \mathrm{C}$ to $90{ }^{0} \mathrm{C}$ with an interval of $5{ }^{0} \mathrm{C}$. It can be seen from Figure 1 that the thickness goes on increasing with bath temperature; it reaches maximum thickness at $65^{0}$ $\mathrm{C}$ and further decreases with increase in temperature after $65^{\circ} \mathrm{C}[12-15]$.

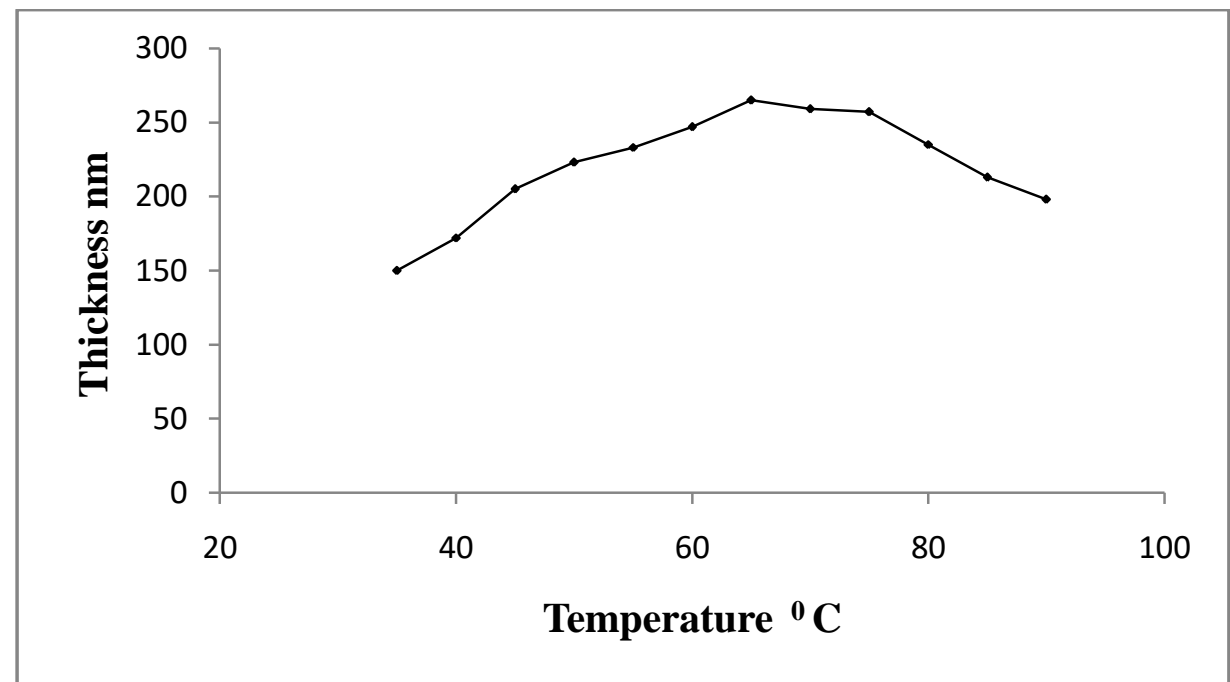

Figure 1: Optimization of solution bath temperature for $\mathrm{Hg}_{x} \mathrm{Cr}_{2-x} \mathrm{~S}_{4}(\mathrm{x}=0.2)$.

\subsubsection{Impact of Molar concentration.}

Figure 2 shows the variation of film thickness with molar concentration, keeping other parameters constant. The molar concentration of chemical bath was changed from $0.02 \mathrm{M}$ to $0.2 \mathrm{M}$ with an interval of $0.02 \mathrm{M}$. It can be seen from Figure 2 that the thickness goes on increasing with molar concentration; the film thickness was reached maximum and then it was constant.

\subsubsection{Impact of Deposition Time}

The impact of deposition time on thickness was studied in Figure 3, keeping the other parameters the same. The thickness of thin film went on increasing with time of deposition, reaching to maximum at 120 minute.

\subsubsection{Impact of Thiourea Concentration}

Figure 4 shows the variation of film thickness with volume of thiourea, keeping other parameters the same. The volume of thiourea was changed into a bath solution. The maximum and well uniformed thin films were obtained with the addition of $10 \mathrm{~mL}$ thiourea into a chemical bath solution. $\mathrm{pH}$ of the chemical bath solution was 10 at room temperature. Figure 4 indicates that the thickness went on increasing with volume of thiourea reaching to maximum $(10 \mathrm{~mL})$ and then decreases with further increase in volume of thiourea. 


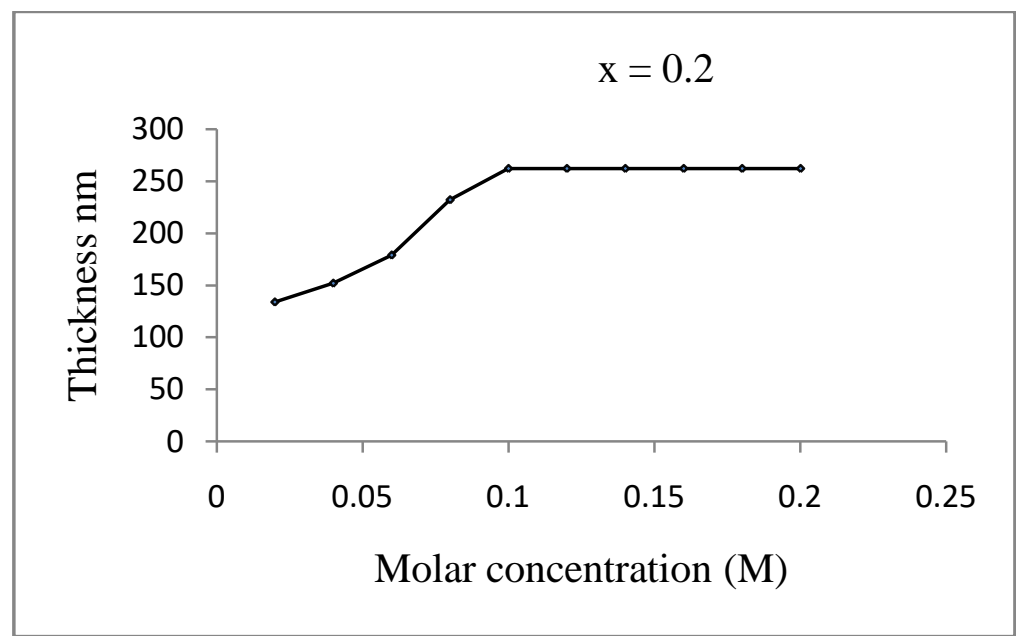

Figure 2: Optimization of molar concentration for $\mathrm{Hg}_{x} \mathrm{Cr}_{2-x} \mathrm{~S}_{4}(\mathrm{x}=0.2)$.

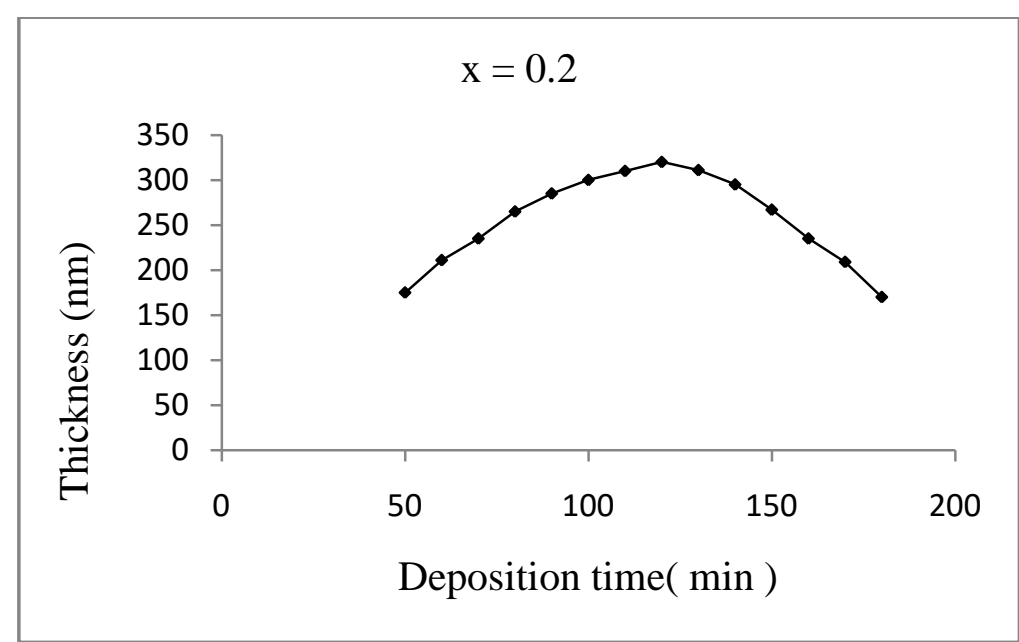

Figure 3: Optimization of deposition time for $\mathrm{Hg}_{x} \mathrm{Cr}_{2-x} \mathrm{~S}_{4}(\mathrm{x}=0.2)$.

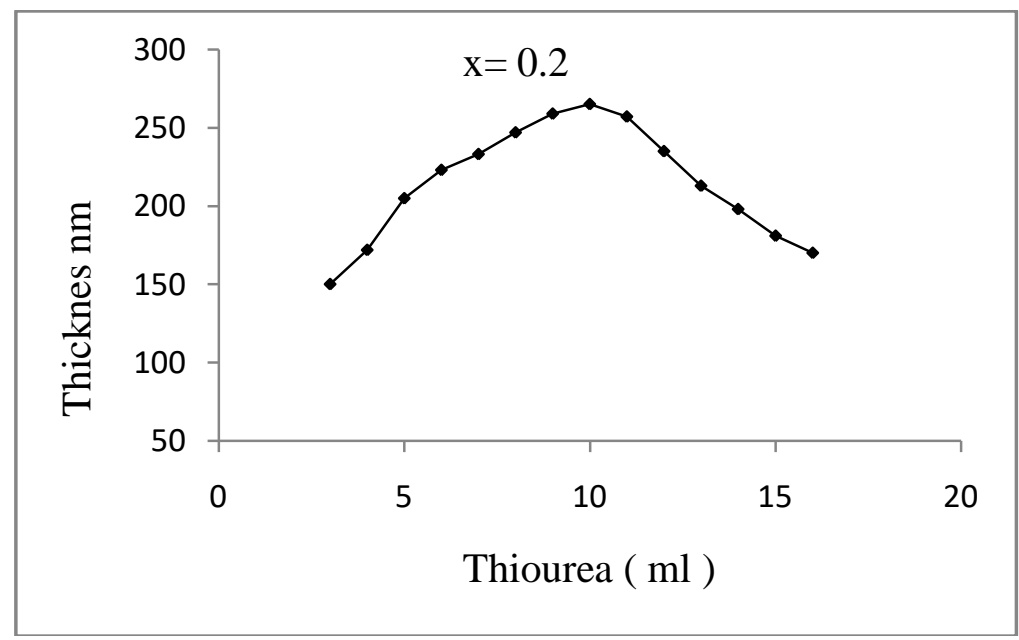

Figure 4: Optimization of thiourea concentration for $\mathrm{Hg}_{x} \mathrm{Cr}_{2-x} \mathrm{~S}_{4}(\mathrm{x}=0.2)$.

\subsection{Structural analysis}

The structural characterization was studied by using X-ray diffraction. The powder X-ray diffraction is performed using Bruker D8 Advanced model, $\mathrm{X}$-ray diffractometer $(\mathrm{CuK} \alpha$ radiation; $\lambda=0.15405 \mathrm{~nm})$. The average crystalline size (D) has been calculated from the line broadening using the Scherer's formula: $D=K$ $\lambda / \beta \cos \theta$, where $\mathrm{K}$ is a constant, $\lambda$ is the wavelength, $\beta$ is full width at half maximum (FWHM) and $\Theta$ is Bragg's angle. 
The XRD pattern of the as- deposited $\mathrm{Hg}_{x} \mathrm{Cr}_{2-x} \mathrm{~S}_{4}(\mathrm{x}=0.2)$ thin films with optimum growth parameters was carried out. It is shown in Figure 5. The observed XRD pattern shows cubic crystal structure with noticeable growth along the (220) plane [15-17], in addition to the other small peaks, namely,(3 111$),\left(\begin{array}{lll}4 & 2 & 2\end{array}\right)$, and $\left(\begin{array}{lll}4 & 4 & 0\end{array}\right)$. Table 1 shows the measured and standard XRD data of d-spacing. There was similarity between measured and standard d-spacing values suggesting the formation of $\mathrm{Hg}_{x} \mathrm{Cr}_{2-x} \mathrm{~S}_{4}$ [18].

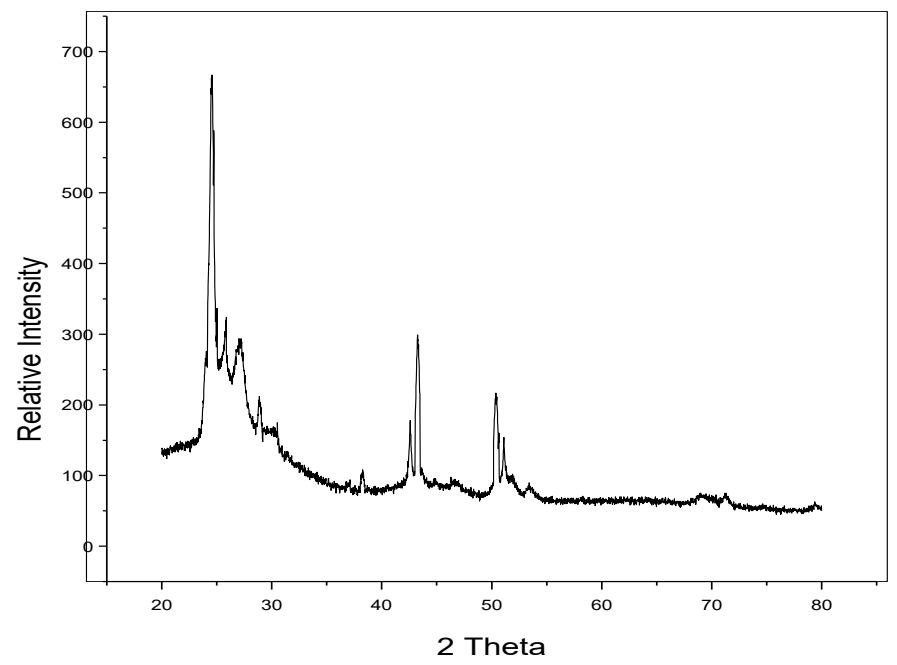

Figure 5 XRD pattern of $\mathrm{Hg}_{x} \mathrm{Cr}_{2-x} \mathrm{~S}_{4}(\mathrm{x}=0.2)$

Table 1

\begin{tabular}{|c|c|c|c|}
\hline h k 1 & \multirow{2}{*}{$\begin{array}{c}|c| \\
\text { degree }\end{array}$} & measured & standard \\
\cline { 3 - 4 } & 24.5800 & 3.61967 & 3.62000 \\
\hline 220 & 28.852 & 3.08123 & 3.0870 \\
\hline 311 & 43.2602 & 2.08982 & 2.09000 \\
\hline 422 & 50.3800 & 1.80983 & 1.81000 \\
\hline 440 & &
\end{tabular}

\subsection{Surface Morphology}

Figure 6 shows SEM image of chemically deposited $\mathrm{Hg}_{\mathrm{x}} \mathrm{Cr}_{2-\mathrm{x}} \mathrm{S}_{4}(\mathrm{X}=0.2)$ thin film. SEM image, confirmed good quality of film formation. From this micrograph, profound observation reveals well resolved, compact grains with irregular shape are cluster structure to form homogeneous surface morphology on substrate surface without void spaces. The grain size measured from SEM image falling in the nanometer range was almost same as that of estimated by XRD studies.

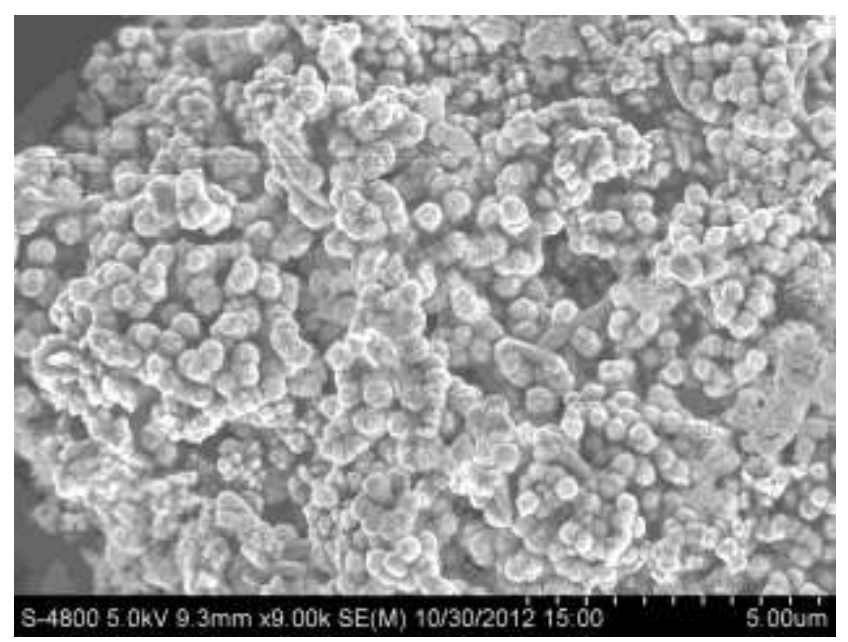

Figure 6 SEM image of $\mathrm{Hg}_{\mathrm{x}} \mathrm{Cr}_{\mathrm{x}-2} \mathrm{~S}_{4}(\mathrm{x}=0.2)$ 


\subsection{Optical properties}

The optical absorption spectra were obtained in the $335 \mathrm{~nm}$ - $800 \mathrm{~nm}$ wavelength ranges by employing a Shimadzu 2450 UV-Visible model of the spectrophotometer. Figure 7a shows the optical absorbance spectra versus wavelength range $\mathrm{nm}$ of the films deposited in this work. The fundamental absorption edge is one of the most important features of the absorption spectrum of a semiconductor. The increased absorption near the edge is caused by the transition of electron from the valance band to conduction band. Optical energy band gap $\left(\mathrm{E}_{\mathrm{g}}\right)$ can be calculated using the relation [19].

$$
\alpha=\frac{A(h v-E g)^{n}}{h v}
$$

Where ' $\mathrm{A}$ ' is a constant and ' $h v$ ' is the photon energy and $\mathrm{n}=2$ for indirect band gap and $\mathrm{n}=1 / 2$ for direct band gap.

Figure $7 \mathrm{~b}$ shows the plot of absorption coefficient $\alpha$ against photon energy. The value of fundamental absorption edge from the intercept lies at 1. 1.5600-3.6494 eV and the corresponding absorption coefficient values were $5.605 \times 10^{5}$ to $9.040 \times 10^{5} \mathrm{~cm}^{-1}$ supporting direct transition of the material [14, 20]. The higher value of absorption coefficient in the UV region makes the material useful in forming p-n junction, solar cells with other suitable thin film materials for photovoltaic applications [21]. Figure 7c shows $(\alpha h v)^{2} \times 10^{12}$ verses photon energy (hv) for $\mathrm{Hg}_{\mathrm{x}} \mathrm{Cr}_{\mathrm{x}-2} \mathrm{~S}_{4}(\mathrm{x}=0.2)$ thin film, optical band gap was obtained by extrapolating these curve. The direct optical energy band gap of this sample was $2.139 \mathrm{eV}$. The reported values in literature are 2.39- $2.70 \mathrm{eV}[14,20]$.

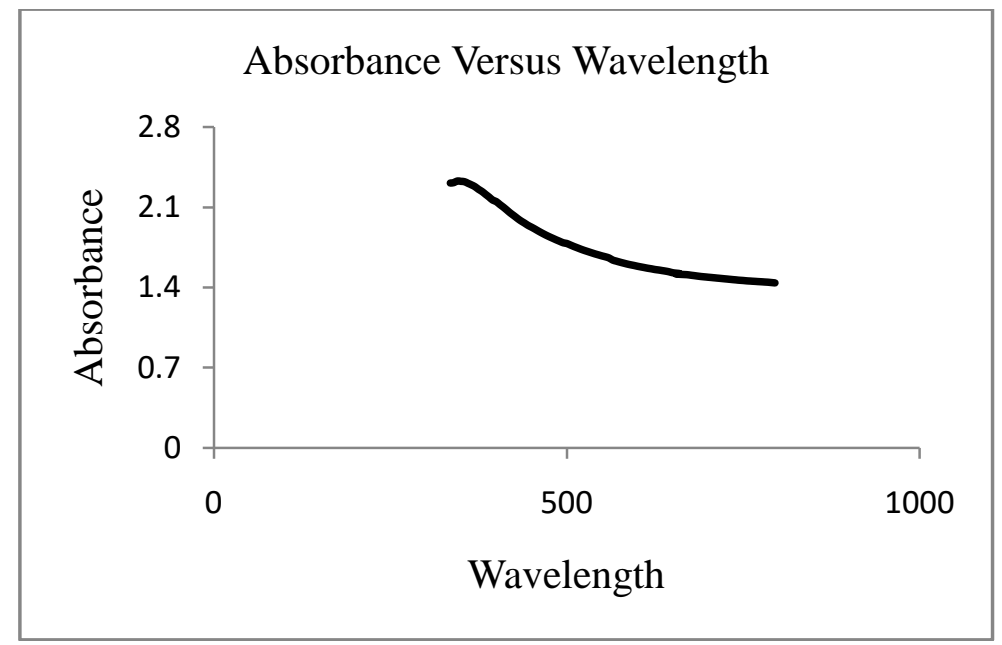

Figure 7 a Absorbance Vs Wavelength

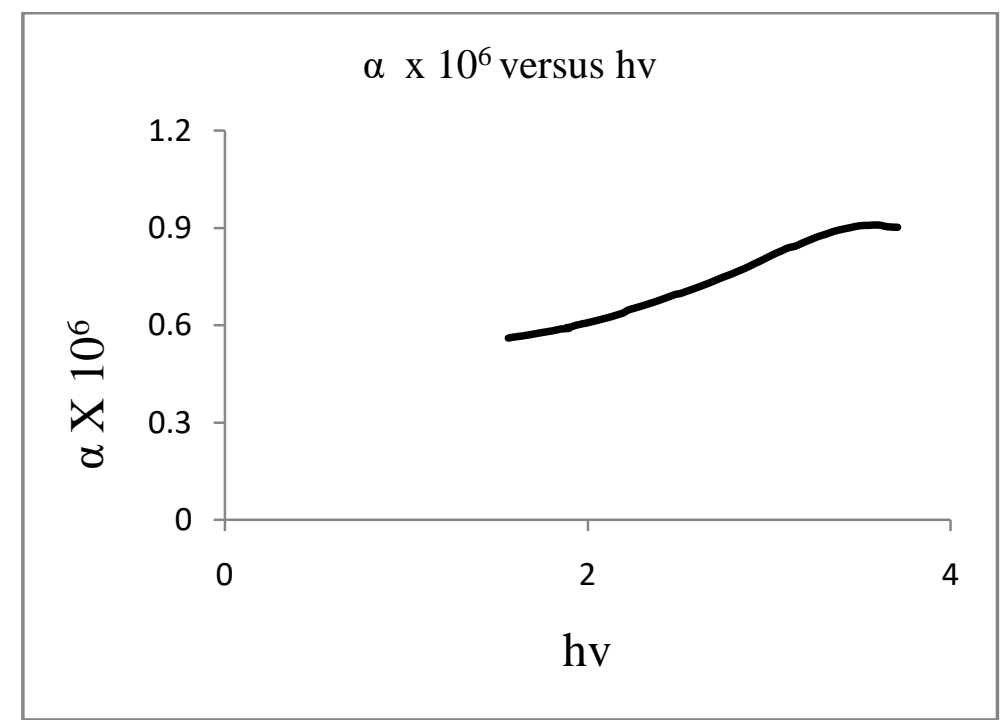

Figure 7b Absorbance coefficient Vs Photon energy 


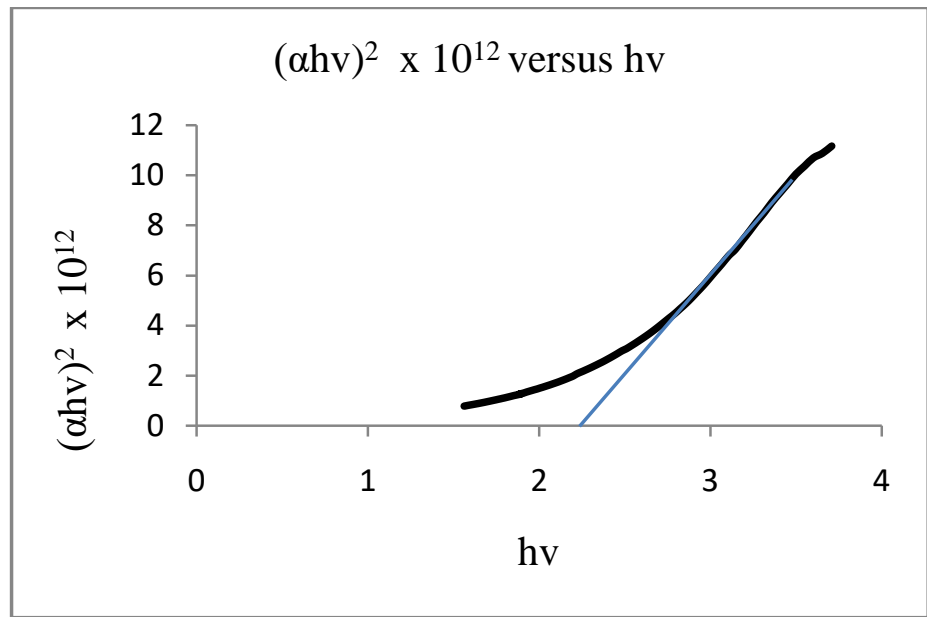

Figure 7c $(\alpha \mathrm{hv})^{2}$ Vs Photon energy(hv).

\subsection{Thermoelectric power}

In the thermo e.m.f. measurement, the temperature difference causes the transport of carriers from the hot end to the cold end and thus creates an electric field, which gives the thermal voltage. This thermally generated voltage is directly proportional to temperature difference created across the semiconductor. Thermoemf generated by the $\mathrm{Hg}_{\mathrm{x}} \mathrm{Cr}_{\mathrm{x}-2} \mathrm{~S}_{4}(\mathrm{x}=0.2)$ thin film was measured in the temperature range $308-423 \mathrm{k}$ and the graphical representation of thermoemf verses change in temperature is as shown in figure 8 . The plot shows that the thermoemf increased with temperature in the sample, which can be attributed to increase in carrier concentration and mobility of charge carriers with temperature. The positive value of thermoelectric emf found over the entire temperature range studied that the majority charge carriers are hole and electron as a minority carriers i.e. p-type behavior.

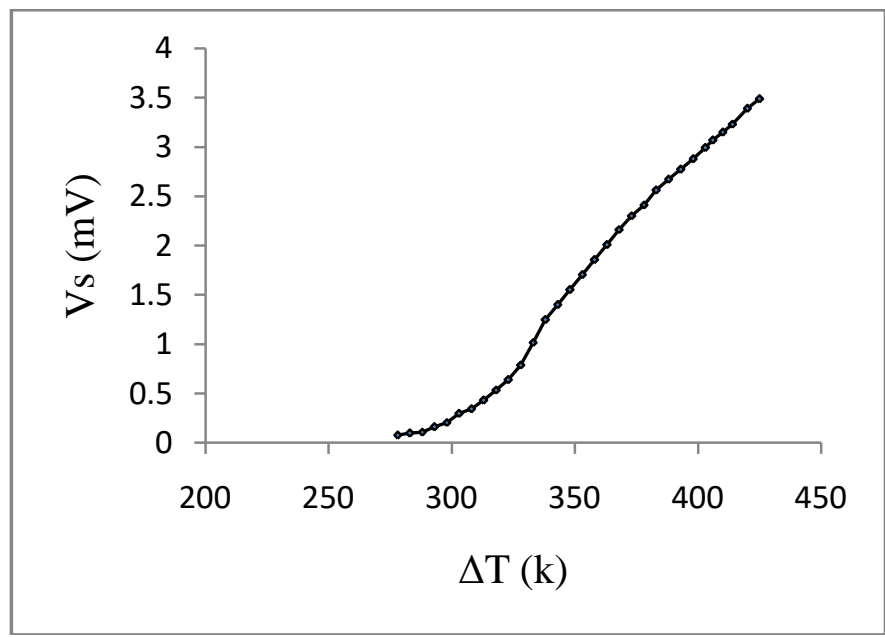

Figure 8 Thermoemf verse $\Delta \mathrm{T}$ for as-deposited $\mathrm{Hg}_{\mathrm{x}} \mathrm{Cr}_{\mathrm{x}-2} \mathrm{~S}_{4} \mathrm{x}=0.2$ ) thin film onto glass substrate.

\section{Conclusion}

$\mathrm{Hg}_{\mathrm{x}} \mathrm{Cr}_{\mathrm{x}-2} \mathrm{~S}_{4}(\mathrm{x}=0.2)$ thin films have been successfully deposited by the simple and inexpensive chemical bath deposition method. The effect of various preparative parameters such as deposition temperature, molar concentration, deposition time and thiourea concentration on growth process is studied. XRD analysis confirms that the deposited films are cubic in nature. A well defined grains with closed packed structure and homogeneous film was observed by surface morphology. The size of grains mostly falls into nanometer range. The direct optical energy band gap of this sample was $2.213 \mathrm{eV}$. From TEP measurement the deposited films are of P- type semiconducting in nature.

\section{Acknowledgement}

The authors are grateful to Prof. P.P.Patil, Vice Chancellor, North Maharashtra University, Jalgaon. The author (HBP) is thankful to the President Shri Amarishbhai patel, the Chairman Shri Rajgopal Bhandari and the Principal, Dr. D.R.Patil, R.C.Patel ASC College,Shirpur for their valuable guidance.. 


\section{References}

[1]. M.A.Mahdi, S. J.Kasem, J. J.Hassen, A. A. Swadi, and S.K. J.A. I-Ani, "Structural and optical properties of chemical deposition CdS thin films," International Journal of Nanoelectronics and Materials, vol. 2, pp. 163-172, 2009.

[2]. Multiple pressure-induced transitions in $\mathrm{HgCr} 2 \mathrm{~S} 4$, Ilias Efthimiopoulos, Alexander Yaresko, Vladimir Tsurkan,, Joachim Deisenhofer, Alois Loidl, Changyong Park, Yuejian Wang, Applied Phy. Letts. 103, 201908 (2013).

[3]. S. Weber, P. Lunkenheimer, R. Fichtl, J. Hemberger, V.Tsurkan, A. Loidl, "Colossal Magnetocapacitance and Colossal Magnetoresistance in HgCr2S4, Phys. Rev. Lett. 96, 157202, 2006.

[4]. T. Kimura, T. Goto, H. Shintani, K. Ishizaka, T. Arima, and Y. Tokura, "Magnetic control of ferroelectric polarization," Nature, vol. 426, no. 6962, pp. 55-58, 2003.

[5]. N. Hur, S. Park, P. A. Sharma, J. S. Ahn, S. Guha, and S.-W. Cheong, "Electric polarization reversal andmemory in amultiferroic material induced by magnetic fields," Nature, vol. 429, no. 6990, pp. 392-395, 2004.

[6]. T. Lottermoser, T. Lonkai, U. Amann, D. Hohlwein, J. Ihringer, and M. Fiebig, "Magnetic phase control by an electric field," Nature, vol. 430, no. 6999, pp. 541-544, 2004.

[7]. T.Goto,T.Kimura,G. Lawes, A. P. Ramirez, andY.Tokura, "Ferroelectricity and giant magnetocapacitance in perovskite rareearth manganites," Physical Review Letters, vol. 92, no. 25, pp.257201-257204, 2004.

[8]. M. Jelonek, A. Winiarski, A. Chelkowski, Phys. Status Solidi A 57,K5, 1980.

[9]. P. P. Sahay, R. K. Nath, and S. Tewari, "Optical properties of thermally evaporated CdS thin films," Crystal Research andTechnology, vol. 42, no. 3, pp. 275-280, 2007.

[10]. D. C. Cameron, W. Duncan, and W. M. Tsang, "The structural and electron transport properties of CdS grown by molecular beam epitaxy," Thin Solid Films, vol. 58, no. 1, pp. 61-66, 1979.

[11]. G. Hodes, Chemical Solution Deposition of Semiconductor Films. Marcel Dekker, Inc, New York, 2002.

[12]. S. H. Pawar and C. H. Bhosale, "Electrochemical bath deposition technique: deposition of CdS thin films," Bulletin of Materials Science, vol. 8, no. 3, pp. 419-422, 1986.

[13]. V. Balasubramanian, N. Suriyanarayanan, and S. Prabahar, "Thickness-dependent structural properties of chemically deposited Bi2S3 thin films," Advances in Apllied Science Research,vol. 3, no. 4, pp. 2369-2373, 2012.

[14]. R. S. Mane, V. V. Todkar, C. D. Lokhande, S. S. Kale, and S.-H. Han, "Growth of crystalline HgCr2S4 thin films at mild reaction conditions," Vacuum, vol. 80, no. 9, pp. 962-966, 2006.

[15]. H.B.Patil, S.V.Borse, "Optimization of Chemical Bath Deposited Mercury Chromium Sulphide Thin Films on Glass Substrate, Indian Journal of Material Science, vol. 1, 4 pages ID 694357,2013.

[16]. R S Mane, V V Todkar, C D Lokhande, Ju-Hyun Ahn and Sung-Hwan Han, "Influence of strain on the surface wettability in crystalline $\mathrm{HgCr} 2 \mathrm{~S} 4$ thin films, Nanotechnology 17 5393-5396, 2006.

[17]. JCPDS card no. 027-0316.

[18]. V. V. Todkar, R. S. Mane, C. D. Lokhande, and S.-H. Han, "p-Type crystalline $\mathrm{HgCr}_{2} \mathrm{~S}_{4}$

[19]. Semiconductor electrode synthesis and its photoelectrochemical studies," Journal of Photochemistry and Photobiology A, vol. 181, no. 1, pp. 33-36, 2006.

[20]. X.Mathew, P.J.Sebastain, Solar Energy mater. Solar Cells, 59,85, 1999.

[21]. R.S. Mane, B.R. Sankapal, K.M. Gadave, and C.D. Lokhande, "Preparation of $\mathrm{CdCr}_{2} \mathrm{~S}_{4}$ and $\mathrm{HgCr}_{2} \mathrm{~S}_{4}$ thin films by chemical bath deposition, Materials Research Bulletin, Vol. 34, Nos. 12/13, pp. 2035-2042, 1999.

[22]. H.B.Patil, S.V.Borse, K.S.Chaudhari, " Optical properties of $\mathrm{HgCr}_{2} \mathrm{~S}_{4}$ thin film deposited by chemical bath deposition method, Invertis J. of Renewable energy,Vol.2,No. 2, pp. 1-5, 2012. 